\title{
Mass Production of Silkworm (Bombyx mori L.) uzi fly Exorista bombycis (Louis)
}

\author{
K. Vasudha Prabhakar, G. V. Vishaka and T. K. Narayanaswamy* \\ Department of Sericulture, University of Agricultural Sciences, GKVK, \\ Bangalore-65, Karnataka, India \\ *Corresponding author
}

\section{A B S T R A C T}

\section{Keywords}

Mass production, pupal weight, pupal length, Silkworms and mated female uzi flies

\section{Article Info}

Accepted:

30 October 2017

Available Online:

10 December 2017
The studies conducted on the mass production of uzipupae by providing silkworm as host. The different number of worm's viz., 50, 100, 200 and 300 fourth instar worms were provided. Among the various parameters studied viz., number of eggs laid (657.00), number of maggots formed (562.00), number of pupae formed (544.00) and number of adult flies emerged (534.00) was found maximum when 300 silkworms were provided as host, followed by 200 silkworms supplied batches. The minimum number of malformed pupae (10.00) was observed in 300 silkworms supplied batches. However, number of eggs laid by 2 mated female uzi flies was inversely proportional to the number of silkworms, whereas maximum number of eggs (657.00) was laid by 2 mated femaleuzi flies, when 300 fourth instar silkworms were provided. The maximum male uzi fly pupal and female pupal weight was observed in 300 worms supplied batches i.e., $1.26 \mathrm{~g}$ and $0.96 \mathrm{~g}$. The minimum was observed in 50 silkworms supplied batches i.e., $0.56 \mathrm{~g}$ and $0.44 \mathrm{~g}$. However, the maximum male pupal length and female pupal length was observed in 300 worms supplied batches i.e., $0.91 \mathrm{~cm}$ and $0.97 \mathrm{~cm}$.

\section{Introduction}

Indian uji fly, E. bombycis is a larval endoparasitoid of the mulberry silkworm. It causes crop loss of 13- 16 per cent in rainy season followed by winter 11-15 per cent and $1.0-3.0$ per cent in summer seasons (BonthaKasi Reddy and Jemmy Venkata Krishna Rao, 2009). An important result of uzi fly research over the last decade is on attempts made on use of sterility techniques. The results of SIT help to successful eradication of Silkworm uzi flies.

The basic requirements for an effective SIT program include the development of mass rearing methods. These methods have been developed for a number of fruit fly species. Recently, the effect of gamma radiation on adult emergence, longevity, reproductive potential and mating competitiveness of the flies was studied (Katiyar et al., 2007).

But work on the mass rearing approaches was not initiated by any researchers till today, for the first time an attempt was made to standardize the number of silkworms required to produce optimum number of healthyuzi maggots.

This can be further used for inducing sterility in uzi fly. 


\section{Materials and Methods}

\section{Mass culturing approaches for uzi flies}

The present study was conducted for culturing of healthy uzi pupae by using silkworm as host.

The mated female uzi flies were released on fourth instar silkworms for egg laying under laboratory conditions in the following way.

The fourth instar silkworms of PM $\times \mathrm{CSR}_{2}$ were used for oviposition. Two mated female uzi flies were released on different number of fourth instar silkworms viz., 50, 100, 200 and 300 , three replications per batch was maintained. The following observations were recorded.

\section{Number of eggs laid}

The day wise fecundity of the female flies was counted between depositions of first egg till the completion of oviposition.

\section{Number of Maggots formed}

It was calculated by counting the number of black scars developed on the silkworm body.

\section{Number of Pupae formed}

It was calculated by counting the number of pupae formed out of number of black scars formed.

\section{Number of Adult emerged}

It was calculated by counting the number of adult flies emerged out of the pupae formed.

\section{Number of Malformed pupae}

It was calculated by counting the number of malformed pupae out of total pupae formed

\section{Pupal weight g}

The male and female pupae after recovery from the mass rearing were separated. Male and female pupa was used for tabulating the weights by using the weighing balance.

\section{Pupal length cm}

The male and female pupae were collected from mass rearing and it is separated, then length of male and female pupae was recorded by using measurement scale.

\section{Results and Discussion}

In the mass production studies the main objective was to produce healthy maggots which can be further used for inducing sterility in uzi fly.

In the mass production activity among the different numbers of worms provided for egg laying, the maximum number of eggs laid was 657 , number of maggots formed was 562, number of pupae formed was 544 and number of adults emerged was 534 recorded, when 300 silkworms were provided as host for two mated female uzi flies (Table 1). This showed that 300 silkworms were found to be optimum to serve as host for egg laying by 2 females and the parameters required for using those mass produced pupae for sterility was also achieved. There is a paucity of literature available to discuss the details of progeny production of uzi flies. But several researches have worked on some other aspects viz., mass production of Tetrastichushowardi on house fly (Kumar Vinod et al., 2012).

The weight of male uzi fly pupa was $0.56 \mathrm{~g}$ and female was $0.44 \mathrm{~g}$ that emerged out of a batch of 50 silkworms, but the pupal weight of male pupa was $0.76 \mathrm{~g}$ and female pupa was $0.67 \mathrm{~g}$ when a batch of 100 silkworms were supplied as host. When a batch 200 silkworms 
were supplied as host the male pupa weighed was $0.89 \mathrm{~g}$ and female pupal weight was 0.77 g. When a batch of 300 silkworms was supplied as hosts the male pupal weight was $1.26 \mathrm{~g}$ and female pupal weight was $0.96 \mathrm{~g}$ (Table 2).

Table.1 Progeny production by mated female uzi flies

\begin{tabular}{|c|c|c|c|c|}
\hline \multirow{2}{*}{ Observations } & \multicolumn{4}{|c|}{ 2 mated female uzi flies } \\
\cline { 2 - 5 } & $\mathbf{5 0}$ worms & $\mathbf{1 0 0}$ worms & $\mathbf{2 0 0}$ worms & 300 worms \\
\hline No. of eggs laid & 143.00 & 327.00 & 493.00 & 657.00 \\
\hline No. of maggots formed & 135.00 & 234.00 & 385.00 & 562.00 \\
\hline No. of pupae formed & 126.00 & 203.00 & 377.00 & 544.00 \\
\hline No. of adults emerged & 110.00 & 150.00 & 345.00 & 534.00 \\
\hline No. of malformed pupae & 016.00 & 053.00 & 032.00 & 010.00 \\
\hline F-test & $*$ & $*$ & $*$ & $*$ \\
\hline SEm \pm & 1.12 & 1.84 & 1.66 & 1.77 \\
\hline CD at 5\% level & 3.27 & 5.81 & 5.23 & 5.57 \\
\hline
\end{tabular}

Note: *Significant at $5 \%$ level

Table.2 Pupal weight and length during mass production

\begin{tabular}{|c|c|c|c|c|}
\hline \multirow{2}{*}{ Treatments } & \multicolumn{2}{|c|}{ Weight g of pupa } & \multicolumn{2}{c|}{ Length cm of pupa } \\
\cline { 2 - 5 } & Male & Female & Male & Female \\
\hline $\begin{array}{c}2 \text { mated female uzi } \\
\text { flies/50 worms }\end{array}$ & 0.56 & 0.44 & 0.57 & 0.62 \\
\hline $\begin{array}{c}2 \text { mated female uzi } \\
\text { flies /100 worms }\end{array}$ & 0.76 & 0.67 & 0.68 & 0.67 \\
\hline $\begin{array}{c}2 \text { mated female uzi } \\
\text { flies /200 worms }\end{array}$ & 0.89 & 0.77 & 0.75 & 0.78 \\
\hline $\begin{array}{c}2 \text { mated female uzi } \\
\text { flies /300 worms }\end{array}$ & 1.26 & 0.96 & 0.91 & 0.97 \\
\hline Control & 1.28 & 1.09 & 0.95 & 1.00 \\
\hline F-test & $*$ & $*$ & $*$ & $*$ \\
\hline SEm \pm & 0.07 & 0.13 & 0.09 & 0.13 \\
\hline CD at 5\% level & 0.22 & 0.58 & 0.42 & 0.45 \\
\hline
\end{tabular}

Note: *Significant at 5\% level.

The length of male uzi fly pupae was $0.57 \mathrm{~cm}$ and female was $0.62 \mathrm{~cm}$ emerged out of 50 silkworms but the pupal length of male pupa was $0.68 \mathrm{~cm}$ and female pupa is $0.67 \mathrm{~cm}$ when a batch of 100 silkworms were supplied as host. When 200 silkworms were supplied as host the male pupal length was $0.75 \mathrm{~cm}$ and female pupal length was $0.78 \mathrm{~cm}$. When 300 silkworms were supplied as host the male pupal length was $0.91 \mathrm{~cm}$ and female pupal length was $0.97 \mathrm{~cm}$. The maximum male uzi fly pupal and female pupal weight was observed when 300 worms supplied batches i.e., $1.26 \mathrm{~g}$ and $0.96 \mathrm{~g}$.

The minimum was observed when 50 silkworms supplied batches i.e., $0.56 \mathrm{~g}$ and $0.44 \mathrm{~g}$. However, the maximum male pupal length and female pupal length was observed when 300 worms supplied batches i.e., 0.91 
$\mathrm{cm}$ and $0.97 \mathrm{~cm}$. The lowest was observed when 50 silkworms supplied batches $i$.e., 0.57 $\mathrm{cm}$ and $0.62 \mathrm{~cm}$. This showed that, supply of 300 silkworms resulted in producing healthy pupae which can be further used in sterility studies. There is less scope for discussion due to non-availability of literature on mass production of uzi flies in the laboratory.

The results on the mass production of uziflies revealed that 300 silkworms/ 2 mated female uzi flies help to produce optimum number of healthy uzi maggots which can be used effectively in SIT of Uzi flies.

\section{Acknowledgement}

I am thankful to UGC, New Delhi, for providing financial assistance, required support and facility for the project Entitled, "Induction of male sterility in silkworm uzi fly, Exorista bombycis (Louis) - A parasitoid of silkworm, Bombyx mori L."

\section{References}

Bontha Kasi Reddy and Jemmy Venkata Krishna Rao, 2009, Seasonal occurrence and control of silkworm diseases, grasserie, flacherie and muscardine and insect pest, uzi fly in Andhra Pradesh, India. Int. J. Indust. Entomol., 18(2):5761.

Katiyar, R. L., manjunath, D., Sathya Prasad, K., Ram Kishore and Datta, R.K., 2007, Induction of sterility in the uzi fly, Exoristabombycis (Louis) through gamma irradiation, Uttar Pradesh. $J$. Zool., 27 (3):271-278.

Kumar Vinod, Singh Amardev and Malhotra Kiran, 2012, Mass production of Tetrastichusha wardii on house fly a pupal parasitoid of leaf roller- A pest of mulberry plant. International research Journal of Biological Sciences, 1(8):3639.

\section{How to cite this article:}

Vasudha Prabhakar K., G. V. Vishaka and Narayanaswamy T. K. 2017. Mass Production of Silkworm (Bombyx mori L.) uzi fly Exorista bombycis (Louis). Int.J.Curr.Microbiol.App.Sci. 6(12): 5412-5415. doi: https://doi.org/10.20546/ijcmas.2017.612.505 